\title{
is Research Soure \\ Preference for Initiation of End-of-Life Care Discussion: a quantitative study
}

\section{Venita Eng ( $\nabla$ venita.w@gmail.com )}

Indonesian Cancer Foundation Jakarta Chapter https://orcid.org/0000-0002-8089-6155

\section{Victoria Hewitt}

Newcastle University

\section{Aria Kekalih}

University of Indonesia: Universitas Indonesia

\section{Research article}

Keywords: end-of-life care, communication, preference, developing countries, online questionnaire

Posted Date: November 18th, 2020

DOI: https://doi.org/10.21203/rs.3.rs-109672/v1

License: (1) This work is licensed under a Creative Commons Attribution 4.0 International License. Read Full License 


\section{Abstract}

Background: Initiating discussion about end of life is often considered a difficult topic for healthcare providers, thus there is a need for further research to understand this area, particularly in developing countries. This study seeks to describe preferences for the initiation of end-of-life care conversations in Indonesia, comparing the general population and health care professionals.

Methods: This study was a cross-sectional descriptive study to gain quantitative data utilizing a questionnaire distributed online. There was a total of 368 respondents (254 general population (69\%); 114 healthcare professionals (31\%)) with a consecutive sampling method.

Result: Overall, most respondents (80.4\%) would like to discuss the end of life issues with a healthcare professional in case of terminal illness. This was more marked amongst health care professionals compared with the general population ( $94 \%$ vs. $75 \%$, respectively, $p<0,001)$. The preferred time for discussion was at first diagnosis $(63 \%)$ or the request of the patients $(27 \%)$, and the preferred person to start the discussion was the doctor (64\%). Depth of information varies as fewer respondents would want to know about prognosis than diagnosis $(76 \%$ v $93 \%)$.

Conclusion: Doctors have vital role in end-of-life care discussion, and attempts should be made to encourage physicians to initiate end-of-life care discussion when needed. Further qualitative study in this topic would help to create a practical guideline to aid physicians in end-of-life care discussion.

\section{Background}

There is a worldwide concern that healthcare quality is remarkably affected by how patients express their personal preferences, especially in end-of-life care settings. ${ }^{1,2}$ End-of-life care applies to patients with advanced incurable disease in which death is expected within 12 months and consists of the palliative approach to enable living as actively as possible and to die with dignity. ${ }^{3}$ End-of-life discussions comprise options for treatment, place, healthcare personnel, and other choices to ensure comfort and good quality of life. ${ }^{2}$

\subsection{Barriers to discussing end of life care}

The UK's National Institute for Health and Care Excellence guideline for adult end-of-life care, recommends that the care received should be "aligned to patient needs and preferences" with "increased length of time spent in preferred place of care". However, many patients are not communicating their preferences to their doctors or caregiver, ${ }^{4}$ due a range of reasons including incapability, ${ }^{5}$ absence of initiation of discussion by health care professionals and lack of resource and education. There is also a concern that as a patient deteriorates, their ability to make independent and autonomous decisions is hindered. Therefore it is encouraged that the discussion should be started in early stage of the disease. ${ }^{5}$ Reluctance to initiate conversation in fear of causing emotional harm to the patient often results in discussions beginning late in the progression of disease. Clinician-related barriers to conversation include 
lack of experience and resource, cultural differences, difficulty in prognostication, and perceived reluctance of patient or family member. ${ }^{6}$

\subsection{Developing countries}

In consideration that lack of communication will result in poor care quality and lower patient satisfaction, the need for further exploration in end-of-life care preference as a basis for practice recommendations and guidelines is warranted. ${ }^{7}$ It is also interesting to note that most research regarding autonomy and preferences in end-of-life care was done in developed countries, and only little data found in developing countries, despite the greater burden of advanced disease in these settings. ${ }^{8}$

This study is conducted in Indonesia, a country in which the increasing burden of terminal illness due to advanced chronic disease is increasing more than $10 \%$ in 4 years, ${ }^{9}$ in the context of limited resource for good palliative and end-of-life care. ${ }^{10}$ Furthermore, research regarding end-of-life care and, in particular that which focuses on communication of this issues in developing country is scarce. One factor which may hinder this is a belief among Indonesian people that conversations regarding terminal illness and death are taboo and, in common with studies in the wider international context, may cause anxiety or depression. ${ }^{11}$ This is, therefore, the first study in Indonesia, to describe perspectives regarding the initiation of conversations about death and dying from medical and lay perspectives in community setting.

\section{Methods}

The design of this study is cross-sectional descriptive study to gain quantitative data of preferences regarding end-of-life care discussion in the Indonesian population. This is, to our knowledge, the first study to explore the topic of end-of-life care communication in Indonesia.

In the absence of a validated end-of-life tool in Indonesia, a questionnaire in the national language (Bahasa Indonesia) was developed and validated. This underwent face validity with 12 local experts in palliative care and communication. The questionnaire then went through cognitive testing with 10 selected participants from general population.

To test the hypothesis that cultural beliefs would impede discussion of end-of-life care and death, a preliminary survey was conducted in 100 random participants from the general population to explore the magnitude of resistance towards end-of-life care/death discussion. Following this, a pilot study of 338 participants (255 general population, 113 health care professionals) was undertaken.

In this pilot study, the questionnaire was distributed to the general population with consecutive sampling method using Jakpat survey andGoogle form link via a Whatsapp group. Jakpat is an Indonesian Open Survey platform with 611.000 mobile respondents across Indonesia and has conducted over 10.000 online survey for various companies, including LIPI (Indonesian Institute of Sciences) and scientific poster publication. ${ }^{12}$ Participants were all over the age of 21 , the age of consent in Indonesia. Given that 
in Indonesia internet penetration rates in age groups under 40 age groups is considerable higher compared with older age groups (Statistica, 2019), a special criterion was made with Jakpat Survey Company to include $20-30 \%$ of adult above 40 years old as respondents, to avoid falsely skewed results and to better reflect the national statistic for age distribution. The overall target was for 200 respondents, with time limit of two weeks to gather participants.

The same questionnaire was distributed to health care professionals with consecutive sampling method using a WhatsApp group of healthcare professional networks. Members of this group were invited to forward the questionnaire to other health care providers only. The overall target respondents for this group was 100 in consideration of feasibility.

\subsection{Data Analysis}

Statistical analysis using IBM SPSS Statistic tools v.20. Univariate analysis was used to obtain descriptive data to get median and average of numeric data. Normality test of data distribution was performed using coefficient of variance and Kolmogorov smirnov test. Bivariate analysis using chi square test and fisher exact test was used, to compare between general population and health care professional result.

\subsection{Ethical issues}

Approval from the medical ethic committee of Newcastle University was granted prior to study commencement, It was identified as low risk with no further ethical approval required.

All participants in the research were healthy, adult volunteers and were presented beforehand with written explanations of the research, questionnaire, anonymity and data confidentiality. Participants were able to leave the study at any time and required to click an informed consent. There is no conflict of interest to disclose.

\section{Results}

\subsection{Respondent Demographic}

Data was collected from 368 participants, $69 \%$ from general population and 31\% from the health care provider population (Table 3.1), representing 22 of Indonesia's 34 provinces. . The health care provider group consisted of various specialities and professional backgrounds, including general practitioner, resident, dentist, nurse, and medical specialist. The average age of general population respondents was 32 years old for the general population and 29.3 for health care professional respondents, compared with a national average age of 28.6 years.

\section{Table 3.1 Respondent Demographic}


General population

$(n=255)$
Health care provider

$(n=113)$

\begin{tabular}{lcc}
$\begin{array}{l}\text { Age (years) } \\
\text { Income (IDR, in millons) }\end{array}$ & $32(21-70)$ & $29.27 \pm 2.10$ \\
$<3,7$ & $95(37.3 \%)$ & $50(44.2 \%)$ \\
$3,7-10$ & $146(57.3 \%)$ & $37(32.7 \%)$ \\
$10-40$ & $13(5.1 \%)$ & $25(22.1 \%)$ \\
$40-100$ & $0(0 \%)$ & $1(0.9 \%)$ \\
$>100$ & $1(0.4 \%)$ & $0(0 \%)$ \\
Education level & $10(3.9 \%)$ & $0(0 \%)$ \\
Elementary & $13(5.1 \%)$ & $0(0 \%)$ \\
Junior high school & $103(40.4 \%)$ & $1(0.9 \%)$ \\
High school & $5(2 \%)$ & $0(0 \%)$ \\
Diploma 1 & $1(0.4 \%)$ & $0(0 \%)$ \\
Diploma 2 & $26(10.2 \%)$ & $0(0 \%)$ \\
Diploma 3 & $87(34.1 \%)$ & $97(85.8 \%)$ \\
\hline Bachelor/undergraduate & $10(3.9 \%)$ & $15(13.3 \%)$
\end{tabular}

Graduate

Number of children

No child

1

2

3

$>3$

\section{Religion}

Moslem

Christian

Catholic

Hindu

Buddhist

Others

Specialty

General Practitioner

Resident

Specialist

Nurse

Other
$95(37.3 \%)$

$56(22 \%)$

$65(25.5 \%)$

$27(10.6 \%)$

$12(4.7 \%)$

$219(85.9 \%)$

$18(7.1 \%)$

$10(3.9 \%)$

$3(1.2 \%)$

$4(1.6 \%)$

$1(0.4 \%)$
$59(52.2 \%)$

$37(32.7 \%)$

$14(12.4 \%)$

$2(1.8 \%)$

$1(0.9 \%)$
$69(61.1 \%)$

$18(15.9 \%)$

$19(16.8 \%)$

$3(2.7 \%)$

$4(3.5 \%)$

$0(0 \%)$
$43(38 \%)$

$57(50.4 \%)$

$9(8 \%)$

$3(2.7 \%)$

$1(0.8 \%)$

\subsection{Initiation of End-of-life Care Discussion}


Overall, most respondents (80.4\%) stated they would like a healthcare provider to discuss end-of-life care with them, This was more marked in healthcare professionals compared with the general population (94 $\% \vee 75 \%, p<0,001)$ (Table 3.2). The preferred time for discussion was at first diagnosis (63\%) or when patient asks for it (27\%), and the preferred person to start the discussion was the doctor (64\%). Regarding initiation, $64 \%$ respondent believed doctor should instigate the talk, with $1,4 \%$ answering nurse and $0,8 \%$ other healthcare staff.

Table 3.2 Respondents' preference regarding end-of-life care discussion initiation and depth of information. 


\begin{tabular}{llcl}
\hline Question & $\begin{array}{l}\text { General } \\
\text { population } \\
(\mathrm{n}=255)\end{array}$ & $\begin{array}{c}\text { Health care } \\
\text { provider }(\mathrm{n}=113)\end{array}$ & P value \\
\hline
\end{tabular}

\section{Do you want healthcare provider to discuss about End-of-life Care?}

Yes

$190(74.5 \%) \quad 106(93.8 \%) \quad<0.001 *$

If yes. the discussion should start at

First diagnosis ${ }^{\wedge}$

When patient ask for it ${ }^{\wedge} \wedge$

Initiation of therapy^^^

$\begin{array}{ccc}130(68.4 \%) & 55(51.9 \%) & \mathbf{0 . 0 1 7 * *} \\ 39(20.5 \%) & 31(29.2 \%) & \\ 15(7.9 \%) & 12(11.3 \%) & \\ 6(3.2 \%) & 7(6.6 \%) & \\ 0(0 \%) & 1(0.9 \%) & \end{array}$

Right before discharge ${ }^{\wedge \wedge} \wedge$

Other^^^

$0(0 \%)$

$112(58.9 \%)$

$76(71.1 \%)$

$0.036^{* *}$

Doctor $^{\wedge}$

$74(38.9 \%)$

$26(24.5 \%)$

Myself (by my request)^^

$3(1.6 \%)$

$2(1.9 \%)$

Other^^^

$1(0.5 \%)$

$2(1.9 \%)$

In case of terminal illness. do you want to know about

Diagnosis

Yes

$232(91.0 \%)$

$112(99.1 \%)$

0.004*

\section{Life expectancy}

Yes

$186(72.9 \%)$

$94(83.2 \%)$

0.034*

Who else do you wish to know above information?

\begin{tabular}{lccc} 
Spouse & $184(72.2 \%)$ & $100(88.5 \%)$ & $\mathbf{0 . 0 0 1 *}$ \\
\hline parent & $139(54.5 \%)$ & $62(54.9 \%)$ & $0.949^{*}$ \\
\hline Child & $90(35.3 \%)$ & $58(51.3 \%)$ & $\mathbf{0 . 0 0 4 *}$ \\
\hline Friend & $38(14.9 \%)$ & $14(12.4 \%)$ & $0.523^{*}$ \\
\hline Other & $1(0.4 \%)$ & $2(1.8 \%)$ & $0.224^{* *}$ \\
\hline No One & $43(16.9 \%)$ & $4(3.5 \%)$ & $<0.001^{*}$ \\
\hline
\end{tabular}

$$
{ }^{*} \text { chi square }{ }^{* *} \text { fisher test }
$$

Answer categories were served as percentage inside each group (column percentage). Statistical test was done to compare between general population and health care provider population's answers, with significant difference value $(p<0,005)$ in bold

3.3 Diagnosis of end of life and life expectancy 
Almost all participants (93\%) would like to be informed when they were in the terminal phase of their illness , and $76 \%$ would like to know the life expectancy. Compared to the general population, healthcare professionals are more inclined to know the diagnosis ( $99 \% \vee 91 \%$ ) and prognosis ( $84 \% \vee 73 \%)$. Most participants overall would like their spouse or parent to know about their diagnosis (93\%) and life expectancy $(76 \%)$. Health care professionals were more likely to include their offspring than the general population $(51 \% \vee 35 \%, p=0,004)$. Conversely, more respondents from general population would prefer no one else to know the information $(17 \% \vee 4 \%, p<0,001)$.

\section{Discussion}

This study found that majority (80\%) of respondents would like a healthcare professional to discuss endof-life care in case of terminal illness with them. This finding accords with both Clayton et $\mathrm{al}^{13}$ and Belanger et al ${ }^{14}$ arguments for physicians to routinely initiate such discussions and provide time for the patient with terminal illness and family to discuss about end-of-life care. Healthcare professionals were themselves more likely to desire end-of-life care discussion, compared with general population. This may be due to readiness to accept medical information as they are more accustomed to it but it also suggests an implicit acknowledgement of the importance of these conversations.

\subsection{Healthcare professional-related factors}

Our findings concur with Keating et $\mathrm{al}^{15}{ }^{15}$ who investigated the responses of physicians presented with a hypothetical situation of newly diagnosed metastatic cancer In common with this study, we found that most health care professionals expressed a preference to discuss prognosis primarily at the time of diagnosis ( $52 \%$ in our study; $65 \%$ in Keating et al and secondarily when initiated by the patient $(29 \%$ in our study; $15 \%$ in Keating et al). . Furthermore, Keating et al ${ }^{15}$ found that younger physicians indicated they would be more open to discussing end of life and initiating these conversation earlier in the disease trajectory compared with their older counterparts. The majority of healthcare professional in our study were early and mid-career physicians, which may contribute to their apparent eagerness towards initiating and discussing end of life issues. Whether more senior physicians have the similar preferences is open for further exploration. Ang et $\mathrm{al}^{16}$ also describe differences between age groups among Singaporeans regarding regarding end of life care preferences. This study of Singaporeans comprised of mostly young adults and is therefore similar to our study population., Thus we suggest that age is a factor to be considered in further research regarding end of life discussions.

It must be acknowledged that our findings relate to a situation abstracted from authentic practice. In real situations, the evidence is that physicians do not regularly initiate the end of life discussions until late in the course of an illness. Huskamp et al ${ }^{17}$ studied patients with metastatic lung cancer and found that most had no discussion about end of life care within 4-7 months of diagnosis, despite the poor prognosis of $5 \%-24 \%$ for 5 year survival attached to this diagnosis. Another study among heart failure patients also noted that more than half of physicians feel hesitant to mention end-of-life care or perceived that patients were not ready to talk about the issue. ${ }^{18}$ Indeed, only $12 \%$ of physicians reported 
they undertake routine, annual end of life care discussions with their heart failure patients, as as advocated by American Heart Association, ${ }^{19}$ suggesting that clinicians' reluctant to discuss end of life with patients is independent of diagnosis. We found the preference for end of life discussion at diagnosis was higher in the general population compared with health care professionals ( $68 \%$ vs $52 \%$ ), further affirming clinicians' hesitancy to engage in these conversations in early course of disease.

\subsection{Patient-related factors}

The risk of a patient's mental capacity deteriorates as their disease progresses, thus conducting end of life discussions in timely manner is important. Time of initiation of these encounters also affects the potential benefit to the patient in terms of planning care, setting goals, maintaining autonomy and managing expectations and increasing patient and carer satisfaction .Furthermore, avoiding futile treatments protects patients from harm, respects their dignity and saves resources to the wider healthcare economy. ${ }^{20}$ Conversely, late discussion and late referral to hospice is associated with poorer patient quality of life and worse bereavement adjustment. This study adds to the body of evidence recommending initiation of end of life discussions in early course of disease, by demonstrating a preference for this within the general population of Indonesia. We accord with Wright et al ${ }^{21}$ who conclude that physician reluctance exceeds their patient's readiness to discuss the topic early in their disease trajectory.

\subsection{Initiating discussions}

Regarding personnel to initiate discussion, both the general population and health care provider groups wished for their doctor to initiate the discussion Our study found the overwhelming majority of respondents from both groups preferred a doctor to instigate the dialogue. A study by Davison ${ }^{22}$ among patients with end stage renal failure undergoing dialysis found that participants clearly believed physicians were responsible for initiating and guiding advance care planning, as they are seen as primary source of information. Their observation that some participants would accept a nurse or social worker to commence discussion was not confirmed in our study, although Davison includes the caveate that professionals other than doctors were acceptable provided they were involved in the patient's care and the conversation was relevant.

A systematic review by Adams et al ${ }^{23}$ demonstrated strong evidence for the role of nurses in actively brokering information among family members and the health care team for decision making concerning end of life. Indeed the American Nursing Association also stress the importance of Nurse role in advocating patient rights regarding preferences, including in end of life. ${ }^{24}$ We therefore argue for further research to assess physician and family member's perception of the nurses' role in end of lifediscussion, and to better understand physician's real experiences regarding nurse participation.

\subsection{Information sharing}


Our study, concurring with Leydon et al ${ }^{25}$ found that although most people would like to know about diagnosis, fewer wanted information regarding prognosis. Furthermore, we observed a similar difference between preference for knowledge about diagnosis compared with prognosis in both study populations ( $15 \%$ difference in healthcare professionals; $18 \%$ in general population).

According to Walczak, ${ }^{26}$ doctors arereluctant to discuss life expectancy for fear of destroying hope and causing death anxiety and doctors and patients may collude to avoid this discussion. In contrast, Krawczyk and Gallagher ${ }^{27}$ found that by eliciting suspicion of false hope and using confusing euphemisms, prognostic uncertainty may harm the doctor-patient relationship, especially when incongruence between doctor's message and the aggressiveness of care provided is perceived. In retrospective, family member reported that effective communication was related to prognostic information as it helps them to prepare and satisfaction of care was higher. We recommend further exploration of this area of information needs and preferences, in order to improve professionals' confidence in leading conversations about end of life care.

Nevertheless, our study found that the majority of respondents would wish to know about their prognosis adding evidence to the recommendation that physicians initiate intitiating dialogue about end of life early in the disease trajectory, tailoring the amount of information to the patient concerned and as part of an ongoing plan of care involving patient and their family. However in view of the variable depth of information that individuals may be capable of processing in such discussions, physicians must skillfully assess each patient's wish regarding depth of information.

This study also reports preferences forrelated parties to be informed about and involved in end-of-life discussions. Most participants would like their spouse or parent to know about their diagnosis of terminal illness and life expectancy, and a bigger portion of health care professionals wish to include their offspring compared with the general population (51\% v 35\%). This was an unexpected finding and further research into the role of offspring in discussions about the end of their parent's life is warranted.

We observed positive acceptance towards end-of-life care discussion in terminal illness, refuting the negative assumption among Indonesian people regarding communication of death and dying. ${ }^{11}$ Considering that reluctance to talk about end-of-life still exists among physicians, the evidence of this study would hopefuly help to give confidence to healthcare professionals to initiate end-of-life care related discussion earlier in course of disease to achieve better goals of care. The questionnaire used in this study is the first set of end-of-life care related questions tailored to local Indonesian cultural and language setting, and may serve as practical base for further development in this field.

\section{Study Limitations And Suggestion}

This study has a number of limitations, promoting improvements for subsequent research. . First, although the number of respondents $(n=368)$ in the pilot study was adequate for statistical analysis, larger sample number and variation of respondent demographic would give wider factors to analyse in 
consideration of Indonesia's vast and multicultural background. Secondly, this study did not comprehensively explore the effect of senior age on preferences for end of life discussions, because the majority of respondents in this study were young adults.

\section{Conclusions}

This study managed to develop and validate end-of-life care preference questionnaire in Bahasa Indonesia adjusted to local culture. The findings in this study could contribute significantly towards the development of end-of-life care policy and guidelines in developing countries such as Indonesia. In more practical terms, the findings can be used to educate and encourage medical professionals to initiate endof-life care discussion with better confidence. Our observations counter the preconceived taboo of end-oflife conversation among patient and doctors, and would help to create practical guideline to aid physicians in end-of-life care discussion.

\section{Declarations}

\section{Ethics approval and consent to participate}

Approval from the medical ethic committee of Newcastle University was granted prior to study commencement, It was identified as low risk with no further ethical approval required (number : 3571 ).

All participants in the research were healthy, adult volunteers and were presented beforehand with written explanations of the research, questionnaire, anonymity and data confidentiality. Participants were all over the age of 21, the age of consent in Indonesia. Participants were able to leave the study at any time and required to click an informed consent. There is no conflict of interest to disclose.

\section{Consent for publication}

Not Applicable.

\section{Availability of data and materials}

The datasets used and/or analysed during the current study are available from the corresponding author on reasonable request.

\section{Competing interests}

The authors declare that they have no competing interests

\section{Funding}

The funding for this research was supported by Indonesian Cancer Foundation Jakarta Chapter.

\section{Authors' contributions}


VE designed and conducted the study, continued with result analysis, and was primary/major contributor in writing the manuscript.

VH supervised the study design and provided insight for analysis and editing of manuscript.

AK interpreted data and statistical analysis, and provided input for writing.

All authors read and approved the final manuscript

\section{Acknowledgements}

Indonesian Cancer Foundation Board and Staff.

Authors' information (optional)

VE is the Head of Medical Service and Palliative Care Program in Indonesian Cancer Foundation Jakarta Chapter

VH is Curriculum Director MSc programmes in Oncology, Palliative Care and Oncology, Newcaste University, and Specialist Palliative Care Physician

AK is staff from Community Medicine Department Faculty of Medicine Universitas Indonesia and currently is responsible as the Head of Epidemiology and Biostatistics Division

\section{References}

1. The National Institute for Health and Care Excellence website. End of life care for adults. 2019. https://pathways.nice.org.uk/pathways/end-of-life-care-for-people-with-life-limiting-conditions . Accessed July 20, 2020.

2. National Health Service. End of life care. 2018. https://www.nhs.uk/conditions/end-of-life-care/whatit-involves-and-when-it-starts/ .Accessed July 20, 2020.

3. General Medical Council website. Treatment and care towards the end of life :good practice in decision making. 2010. https://www.gmc-uk.org/ethical-guidance/ethical-guidance-fordoctors/treatment-and-care-towards-the-end-of-life .Accessed June 21, 2020.

4. Narang AK, Wright AA, Nicholas LH. Trends in advance care planning in patients with cancer: results from a national longitudinal survey. JAMA Oncol. 2015;1(5):601-608.

doi:10.1001/jamaoncol.2015.19762020

5. Sinuff T, Dodek P, You JJ, et al. Improving end-of-life communication and decision making: the development of a conceptual framework and quality indicators. J Pain Symptom Manage. 2015;49(6):1070-1080. doi:10.1016/j.jpainsymman.2014.12.007.,

6. Travers A, Taylor V. What are the barriers to initiating end-of-life conversations with patients in the last year of life?. Int J Palliat Nurs. 2016;22(9):454-462. doi:10.12968/ijpn.2016.22.9.454 
7. Brighton LJ, Koffman J, Hawkins A, et al. A systematic review of end-of-life care communication skills training for generalist palliative care providers: research quality and reporting guidance. J Pain Symptom Manage. 2017;54(3):417-425. doi:10.1016/j.jpainsymman.2017.04.008

8. Worldwide Palliative Care Alliance. Global atlas of palliative care at the end of life. 2014. https://www.who.int/nmh/Global_Atlas_of_Palliative_Care.pdf . Accessed July 20, 2020.

9. Schröders J, Wall S, Hakimi M, et al. How is Indonesia coping with its epidemic of chronic noncommunicable diseases? A systematic review with meta-analysis. PLoS One. 2017;12(6):e0179186. Published 2017 Jun 20. doi:10.1371/journal.pone.0179186

10. Witjaksono MA, Sutandiyo N, Suardi D for the Indonesian Palliative Society. Regional support for palliative care in Indonesia. Ehospice website. 2014.

www.ehospice.com/Default/tabid/10686/Articleld/11661 .Accessed June 20, 2020.

11. Putranto R, Mudjaddid E, Shatri H, Adli M, Martina D. Development and challenges of palliative care in Indonesia: role of psychosomatic medicine. Biopsychosoc Med. 2017;11:29. Published 2017 Nov 21. doi:10.1186/s13030-017-0114-8

12. Dachyar M, Ilahiyyah EN. determining the importance factors of financial technology adoption in hospital using fuzzy analytical network process (FANP). 2019. in iop conference series: materials science and engineering (Vol. 598, No. 1, p. 012047). IOP Publishing

13. Walczak A, Butow PN, Clayton JM, et al. Discussing prognosis and end-of-life care in the final year of life: a randomised controlled trial of a nurse-led communication support programme for patients and caregivers. BMJ Open. 2014;4(6):e005745. Published 2014 Jun 26. doi:10.1136/bmjopen-2014005745

14. Bélanger E, Rodríguez C, Groleau D, Légaré F, Macdonald ME, Marchand R. Initiating decision-making conversations in palliative care: an ethnographic discourse analysis. BMC Palliat Care. 2014;13:63. Published 2014 Dec 23. doi:10.1186/1472-684X-13-63

15. Keating NL, Landrum MB, Rogers SO Jr, et al. Physician factors associated with discussions about end-of-life care. Cancer. 2010;116(4):998-1006. doi:10.1002/cncr.24761

16. . Ang GC, Zhang D, Lim KH. Differences in attitudes to end-of-life care among patients, relatives and healthcare professionals. Singapore Med J. 2016;57(1):22-28. doi:10.11622/smedj.2016008

17. Huskamp HA, Keating NL, Malin JL, et al. Discussions with physicians about hospice among patients with metastatic lung cancer. Arch Intern Med. 2009;169(10):954-962. doi:10.1001/archinternmed.2009.127

18. Dunlay SM, Foxen JL, Cole T, et al. A survey of clinician attitudes and self-reported practices regarding end-of-life care in heart failure. Palliat Med. 2015;29(3):260-267. doi:10.1177/0269216314556565

19. Allen LA, Stevenson LW, Grady KL, et al. Decision making in advanced heart failure: a scientific statement from the American Heart Association. Circulation. 2012;125(15):1928-1952. doi:10.1161/CIR.0b013e31824f2173 
20. LeBlanc TW, Tulsky MAJ. Discussing goals of care. UpToDate website. Updated October 29, 2018..https://www.uptodate.com/contents/discussing-goals-of-care. Accessed 20 July, 2020

21. Wright AA, Zhang B, Ray A, et al. Associations between end-of-life discussions, patient mental health, medical care near death, and caregiver bereavement adjustment. JAMA. 2008;300(14):1665-1673. doi:10.1001/jama.300.14.1665

22. Davison SN. Facilitating advance care planning for patients with end-stage renal disease: the patient perspective. Clin J Am Soc Nephrol. 2006;1(5):1023-1028. doi:10.2215/CJN.01050306

23. Adams JA, Bailey DE Jr, Anderson RA, Docherty SL. Nursing roles and strategies in end-of-life decision making in acute care: a systematic review of the literature. Nurs Res Pract. 2011;2011:527834. doi:10.1155/2011/527834

24. Rights, ANA Center for Ethics and Human. "Nurses' Roles and Responsibilities in Providing Care and Support at the End of Life." 2016. Nursing World. https://www.nursingworld.org/ 4af078/globalassets/docs/ana/ethics/endoflifepositionstatement.pdf Accessed 1 May 2020.

25. Leydon GM, Boulton M, Moynihan C, et al. Cancer patients' information needs and information seeking behaviour: in depth interview study. BMJ. 2000;320(7239):909-913.

doi:10.1136/bmj.320.7239.909

26. Walczak A, Butow PN, Clayton JM, et al. Discussing prognosis and end-of-life care in the final year of life: a randomised controlled trial of a nurse-led communication support programme for patients and caregivers. BMJ Open. 2014;4(6):e005745. Published 2014 Jun 26. doi:10.1136/bmjopen-2014005745

27. Krawczyk M, Gallagher R. Communicating prognostic uncertainty in potential end-of-life contexts: experiences of family members. BMC Palliat Care. 2016;15:59. Published 2016 Jul 12. doi:10.1186/s12904-016-0133-4 